Elsevier required licence: (c) <2020>. This manuscript version is made available under the CC-BY-NC-ND 4.0 license http://creativecommons.org/licenses/by-nc-nd/4.0/

The definitive publisher version is available online at https://doi.org/10.1016/j.ijggc.2020.103079 


\section{A generic techno-economic optimization methodology for concurrent design and operation of solvent-based PCC processes}

\author{
Kaveh R. Khalilpour ${ }^{1,2^{*}}$, Ali Zafaranloo ${ }^{3}$ \\ ${ }^{1}$ School of Information, Systems and Modelling, University of Technology Sydney, Australia \\ ${ }^{2}$ School of Chemical and Biomolecular Engineering, The University of Sydney, Australia \\ ${ }^{3}$ Faculty of Information Technology, Monash University, Australia \\ *Corresponding author, Emails: kaveh.khalilpour@uts.edu.au
}

\begin{abstract}
A techno-economic equation-based methodology is developed for optimal design and operation of integrated solvent-based post-combustion carbon capture (PCC) processes using a rate-based model for the interaction of gas and liquid. The algorithm considers a wide range of technoeconomic design and operation parameters such as number of absorber/desorber columns, height of columns, diameter of columns, operating conditions (P, T) of columns, pressure drop, packing type, percentage of $\mathrm{CO}_{2}$ mitigated, captured $\mathrm{CO}_{2}$ purity, amount of solvent regeneration, flooding velocities of columns, and number of compression stages. A case study conducted to showcase two common objective-functions i) minimizing total capital investment, and ii) minimizing levelized capture costs, both for a $300 \mathrm{MW}$ coal-power plant in Australia. The former objective leads to the lowest possible total capital cost of $\$ 312.4 \mathrm{M}$ corresponding to levelized carbon capture cost of $58.1 \$ /$ tonne- $\mathrm{CO}_{2}$. For objective (ii), however, the lowest levelized carbon capture cost is found to be around ten percent lower (52.8 $\$ /$ tonne- $\mathrm{CO}_{2}$ ), though it leads to a higher total capital cost $(\$ 325.2 \mathrm{M})$. The results indicate that the design and operation variables are markedly interactive, and no unique optimal design exists which can deliver all desired outcomes at once. Therefore, decisions on the selection of right variables become dependent on the decision-makers techno-economic objectives.
\end{abstract}

Keywords: Climate Change mitigation; post-combustion carbon capture (PCC); process design and economics; process systems engineering; optimization; solvent; MEA. 


\section{Introduction}

2 The World Energy Investment Outlook by the International Energy Agency (IEA) has highlighted

3 that "carbon capture and storage provides an increasingly important hedge for fossil fuel assets

4 against the possibility of under-utilization or early retirement." The IEA suggested that by 2050,

5 in order to stabilize global warming, global $\mathrm{CO}_{2}$ emissions from all fossil fuel energy technologies

6 should be reduced to half of their emissions levels in 2007 (IEA, 2016). Approximately 12\% of

7 the targeted reduction in $\mathrm{CO}_{2}$ emissions could be achieved by applying carbon capture and storage

8 (CCS) technology (IEA, 2016). The UN's Intergovernmental Panel on Climate Change (IPCC) has

9 modelled four pathways on capping global warming at $1.5^{\circ} \mathrm{C}$ (IPCC, 2018). In most of these

10 pathways, the share of fossil fuel power generation with CCS has increased. This is to expand the

11 share of gas (to $\sim 8 \%$ ) to the benefit of reducing the use of coal (to $\sim 0 \%$ ) for global electricity

12 generation in 2050.

13 Amongst the alternatives for carbon capture, solvent-based post-combustion carbon capture (Sol-

14 PCC) technology is known as a feasible option for large-scale CCS projects, since it can be

15 effectively-integrated within fossil fuel-based plants with minimum changes involved, compared

16 with other alternatives (Metz et al., 2005). It is also comparatively reliable due to its several

17 decades of application for enhanced oil recovery (EOR) (Herzog et al., 1997) and currently

18 different other industrial applications such as beverage production (Aaron and Tsouris, 2005;

19 Desideri and Paolucci, 1999). Figure 1 illustrates the schematics of a PCC process. The pre-cooled

20 flue gas passes through the absorber column (packed or tray) where the lean solvent enters from

21 the top of the absorber in a countercurrent course. In the absorber, the solvent removes the $\mathrm{CO}_{2}$

22 from the flue gas through an exothermic physicochemical interaction; the warmer rich solvent then

23 exits from the bottom of the absorber while the cleaned flue gas leaves the absorber overhead

24 towards the stack. In the desorber column, the rich solvent is stripped of $\mathrm{CO}_{2}$ by thermal treatment

25 (solvent re-boiling). The lean solvent is recycled to the absorber column while the $\mathrm{CO}_{2}$ is sent,

26 through the overhead, to the compression unit. 


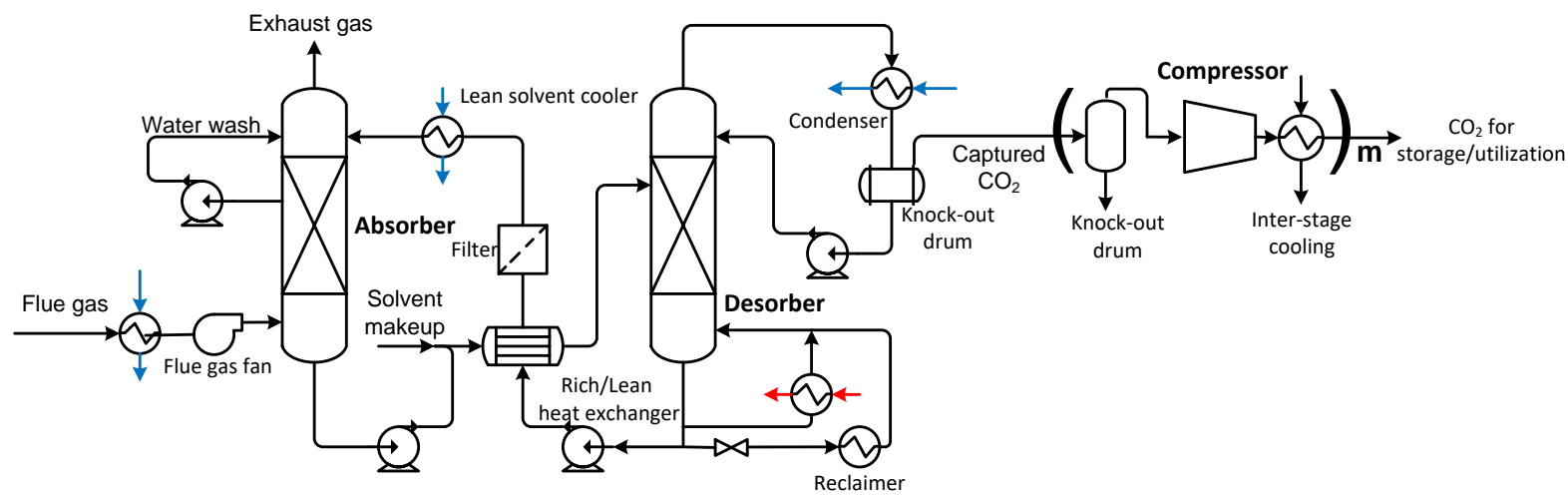

Figure 1: Schematic of the solvent-based PCC process configuration (Wang, 2017).

3 Despite notable developments in Sol-PCC, the implementation of this technology in power plants 4 still experiences notable barriers due to its high capital and operating costs (Biliyok, 2013; Metz 5 et al., 2005; Rubin, 2007). Previous studies (Abu-Zahra, 2007b; Dave, 2011) have indicated that 6 the operating costs come mainly from the desorber's reboiler though the magnitude varies 7 depending on the type of $\mathrm{CO}_{2}$-emitting plant, solvent mix, and different design \& operation 8 features. This energy requirement leads to a significant reduction in overall plant efficiency 9 (Khalilpour and Abbas, 2011; Rubin, 2013; van der Spek, 2017a). Techno-economic studies have 10 shown significant potentials to integrate and improve the feasibility of Sol-PCC technologies (van 11 der Spek, 2017a, b); however, uncertainty and variability in their results known as a major issue 12 with this analysis. Van der Spek et al. (2017b) recently showed that despite several attempts to 13 harmonize techno-economic estimates, the capital cost evaluation for the same PCC process could 14 vary by a large margin of $65 \%$, due to inherent uncertainties in early stages of costing studies. 15 They speculated that these variabilities of capital costs originated from the differences in 16 equipment sizing methods and predictions for equipment costs, which later could be propagated 17 into the levelized cost of electricity and operating costs. Hence, rigorous techno-economic analyses 18 for integration of Sol-PCC processes with $\mathrm{CO}_{2}$-emitting plants seem essential to achieve optimum 19 design and operation conditions. The critical parameters influencing the efficiency of Sol-PCC 20 processes are solvent type, solvent concentration, configuration of absorption and stripping 21 columns, operating conditions of absorption/desorption columns, the percentage of $\mathrm{CO}_{2}$ avoided, 22 captured $\mathrm{CO}_{2}$ purity, and amount of regeneration. Abu-Zahra et al. (2007a) investigated the impact 23 of several parameters using Aspen Plus simulation environment and highlighted the importance of 24 rigorous design optimization for cost reduction of Sol-PCC. Khalilpour and Abbas (2011) provided 
1 a concise summary of various pathways for performance improvement and discussed the great 2 potential of process optimization for improving the overall efficiency of the Sol-PCC process 3 integrated with power plants.

4 It is a legitimate question concerning the lack of rigorous design methodologies for Sol-PCC, given

5 the high industrial demand. The answer is rooted in the absorber and desorber columns' reactive 6 separation. The modeling and design of gas-liquid interaction systems 7 (absorption/desorption/distillation) is a conventional chemical engineering problem. The literature 8 is relatively rich with modeling/design methodologies for absorption/desorption columns with non-reactive interaction (both rate-based and equilibrium). However, when chemical reactions

10 accompany these processes, the so-called reactive absorption/desorption systems become 11 significantly complex (Astarita, 1967, 1983; Danckwerts, 1970). This is due to the high interaction 12 of process thermodynamics, the existence of multiple reactants (some in the ionic state), and 13 mass/heat transfer within the system. For this reason, reactive absorption/desorption systems are 14 not yet fully understood (Kenig and Górak, 2005). The initial interest in reactive separation was 15 derived mainly from the need for natural gas sweetening, e.g., (Danckwerts and Sharma, 1966; 16 Pandya, 1983; Sanyal et al., 1988). In recent decades, however, the number of publications in this 17 field has notably increased with the attention to capturing $\mathrm{CO}_{2}$ from flue gas (Freguia and Rochelle, 18 2003; Mores et al., 2011). Studies in this regard often have been modelled the system with 19 simulators, while others with equation-based models. Nevertheless, there are discrepancies across 20 the simulation software packages. For instance, Luo et al. (2009) compared the results of four 21 different pilot plants with six simulators (Aspen RadFrac/RateSep, Promax, CHEMASIM, 22 Protreat, and CO2SIM) and found that the employed simulators were not capable of predicting 23 consistent results for critical parameters like reboiler duty, concentration and temperature profiles.

24 This deficiency even applies to well-known solvents such as MEA.

25 Furthermore, in recent years there has been a growing trend of rigorous methodologies for the 26 integration of Sol-CCS processes with dynamic electricity market, e.g. (Khalilpour, 2014; Mac 27 Dowell and Shah, 2015). Despite this, very few studies have integrated "operation" models with 28 “design," e.g., (Damartzis et al., 2016; Khalilpour and Abbas, 2014a; Lawal, 2012). In the 29 mainstream literature, modeling tasks are carried out based on an existing pilot plant to find the 30 optimal operating conditions. However, a correct and optimal design task for a new (PCC) plant 31 requires parallel modeling of both process design (heights, diameters, and so forth) and operating 
1 conditions (pressures, temperatures, flow rates, and so forth). This critical approach has received 2 very little attention in the literature concerning PCC (Damartzis et al., 2014), and hence its 3 importance is evident from the high capital expenditure (CAPEX) of a PCC process being close to 4 that of a power plant. Khalilpour and Abbas (2014a) developed an equation-based methodology 5 for optimal synthesis and design of absorption and desorption columns considering the rate-based interaction of the gas and liquid. The design methodology deliberates the influential technoeconomic parameters such as a number of absorber/desorber columns, height, and diameter of 8 columns, operating conditions $(\mathrm{P}, \mathrm{T})$ of columns, pressure drop, packing type, the percentage of $9 \mathrm{CO}_{2}$ avoided, captured $\mathrm{CO}_{2}$ purity, amount of regeneration, and flooding velocities of columns. 10 The authors reported that the design and operation parameters are so markedly interactive that 11 decisions as to the selection of the right values for the variables require techno-economic study 12 and the setting of a unique objective such as NPV (net present value). Then the optimal operation 13 and design parameters could be found under the umbrella of the economic objective function. The 14 users could give the objective function based on their specific goal which might be more towards 15 minimization of capital costs or operational costs. Such goals may vary based on different 16 locations. For instance, CSIRO's study suggests that while the main barrier to the implementation 17 of CCS technologies for energy-importing countries (e.g., China) is to improve the energy 18 efficiency of PCC process, the challenge for developed countries such as Australia is the reduction 19 of process capital expenditures through an optimal process design (Dave, 2011). According to this 20 study, capital costs account for $73 \%$ of the costs of electricity generation with carbon capture in 21 Australia (and similarly developed countries), whereas it is only 33\% for China. It is evident from 22 this example that the design objective for these two design scenarios would be different and thus, 23 the development of an economic model combined with technical variables could assist companies 24 in easier decision-making.

25 In this paper, we aim to provide a generic methodology for supporting techno-economic decision 26 making for optimal synthesis, design, and operation of Sol-PCC systems. The approach developed 27 here concurrently optimizes the critical design and operation variables for achieving the best 28 decision over the lifespan of a plant. 


\section{Problem statement}

2 Consider a $\mathrm{CO}_{2}$-emitting process (e.g., power plant, a steel company, and cement industry) with a 3 baseline flue gas flow rate of $F_{b}^{F G}$. The flue gas composition is known. The given planning horizon

4 is $Y$ years $(y: 1,2, \ldots, Y)$, each year with $T P Y$ total periods of a given fixed length $\Delta \mathrm{t}$ (min, hr, day,

5 week, etc.). The current optimization study is occurring in the base year $(y=0)$.

6 The government has introduced its emission reduction regulations in the form of carbon taxes over 7 a given timeframe, and thus the plant must comply with the new policies. The company has 8 selected Sol-PCC process as its strategic emission reduction approach and is assessing to build a 9 Sol-PCC plant with baseline design capacities of $D C$ tonnes of $\mathrm{CO}_{2}$ capture per period of $\Delta t$, and 10 an annual capacity factor of $C F$. With the addition of a Sol-PCC plant, the company will need 11 extra energy for running the pumps, compressors, and reboilers. If the company is an electricity 12 generator, this excess in-house demand will evidently imply a reduced electricity export. For a 13 power-consuming plant (cement, steelmaking, etc.), this will mean additional power procurement.

14 In a liberalized market, the price of electricity is variable and defined by market dynamics 15 (Khalilpour, 2014). Herein, we assume that the company, with access to historical periodical data, 16 has projected the average pool price of electricity, $E E P_{y}$, at year $y$. The prices of heating energy 17 (for reboiler) and cooling energy are $H E P_{y}$ and $C E P_{y}$, respectively.

18 Our decision-making optimization algorithm is illustrated in Figure 2. Any optimization process 19 consists of a few key components, including assumptions, input parameters, variables, constraints 20 and an objective function.

21 Inputs: Table 1 shows a list of inputs. First, the decision-maker (power plant, steelmaking 22 company, cement industry, etc.) defines the desired decision parameters which are "inputs" to the 23 program (A in Figure 2) including flue gas composition, desired carbon capture rate, preferred list 24 of solvents, column packings, equipment specifications as well as costs.

25 Variables: Table 1 also shows a list of variables. These variables are of two types. Some are 26 directly linked with economic objective function (No 1-9 in Table 1, also presented as a section B 27 in Figure 2). There are however some other variables which are determined in the synthesis/design 28 stage (No 10-33 in Table 1) and are indirectly linked to the objective function. Once the decision29 maker supplied the input parameters, the optimization initiates to find the best combinations of all 30 these variables to achieve the optimal goal. 
Table 1: List of input parameters and unknowns (variables) for the Sol-PCC process system synthesis and design

\begin{tabular}{|c|c|c|c|c|}
\hline Inputs & \multicolumn{4}{|c|}{ Variables } \\
\hline $\begin{array}{l}\text { - Desired rate of } \mathrm{CO}_{2} \\
\text { capture (weight per time) } \\
\text { - Available flue gas flow } \\
\text { rate and its detailed } \\
\text { composition }\left(\mathrm{CO}_{2}, \mathrm{H}_{2} \mathrm{O}, \mathrm{N}_{2} \text {, }\right. \\
\text { etc.) } \\
\text { - Solvent types, } \\
\text { composition, and operating } \\
\text { (T, P) range } \\
\text { - List of candidate packings } \\
\text { and their properties } \\
\text { - List of equipment } \\
\text { suppliers and types (pumps, } \\
\text { compressors, heat exchanger, } \\
\text { drums, etc.) }\end{array}$ & $\begin{array}{l}\text { 1) } \\
\text { 2) } \\
\text { 3) } \\
\text { 4) } \\
\text { 5) } \\
\text { 6) } \\
\text { 7) } \\
\text { 8) } \\
\text { 9) } \\
\text { 10) } \\
\text { 11) } \\
\text { 12) } \\
\text { 13) } \\
\text { 14) } \\
\text { 15) } \\
\text { 16) }\end{array}$ & $\begin{array}{l}\mathrm{CO}_{2} \text { capture efficiency }(\%) \text { of the PCC } \\
\text { plant } \\
\text { Temperature of the inlet flue gas to } \\
\text { absorber } \\
\text { Temperature of the inlet gas to desorber } \\
\text { Temperature of the inlet solvent to } \\
\text { absorber } \\
\text { Lean loadings } \\
\text { Rich loadings } \\
\text { Packing type and size } \\
\text { Pressures of absorber columns } \\
\text { Pressures desorber columns } \\
\text { Number of absorber columns } \\
\text { Column diameter of absorber column } \\
\text { Packing height of absorber column } \\
\text { Size of absorber demister } \\
\text { Solvent flow rate of absorber } \\
\text { Pressure drop of absorber column } \\
\text { Number of desorber columns }\end{array}$ & $\begin{array}{l}17) \\
18) \\
19) \\
20) \\
21) \\
22) \\
23) \\
24) \\
25) \\
26) \\
27) \\
28) \\
29) \\
30) \\
31) \\
32) \\
33)\end{array}$ & $\begin{array}{l}\text { Column diameter of desorber column } \\
\text { Packing height of desorber column } \\
\text { Size (area) of desorber demister } \\
\text { Gas flow rate of desorber } \\
\text { Pressure drop of desorber } \\
\text { Reboiler temperature } \\
\text { Condenser size } \\
\text { Reflux drum size } \\
\text { Reboiler size } \\
\text { Lean/rich Heat-exchanger size } \\
\text { Recycled solvent cooler size } \\
\text { Blower size } \\
\text { Pump size } \\
\text { Number of compressors } \\
\text { Sizes of compressors } \\
\text { Sizes of inter-stage cooling heat } \\
\text { exchangers of compressors } \\
\text { Sizes of pre-compressor knock-out } \\
\text { drums }\end{array}$ \\
\hline
\end{tabular}

3 Constraints: In any techno-economic assessment, there are several constraints involved. These 4 could be high-level economic constraints, such as the maximum available investment budget, or could be technical limitations enforced by the physics or chemistry of the system. For instance, equipment size could theoretically have any value, but manufacturers might supply equipment in certain sizes. Absorber/desorber columns height can take any theoretic magnitude while within a practical perspective, manufacturers often enforce a maximum allowable diameter and height.

9 Objective: Selection of the objective function is the most critical step in any techno-economic assessment and is entirely related to a company's policies and future planning. A correct objective

11 function can guarantee a sustainable solution. An objective function might be merely minimization

12 of total capital investment $\left(\mathrm{C}_{\mathrm{TCI}}\right)$, simply CAPEX, or operating expenditure (OPEX). It could also

13 be the minimization of levelized cost of the product (LCOP), maximization of internal rate of

14 return (IRR), maximization of net present value (NPV) of cash flow, and so forth. The formulation

15 presented in this work is generic, and it offers flexibility for future users to employ the objective

16 function of interest. It is noteworthy that the current appropriate objective functions are the

17 minimization of OPEX, NPV of costs, and levelized costs. This is mostly due to the fact that the

18 carbon capture process is not considered as a lucrative practice as the product of the process $\left(\mathrm{CO}_{2}\right)$

19 doesn't have positive economic value. As such, attentions are mainly toward minimization of 

in Figure 2.

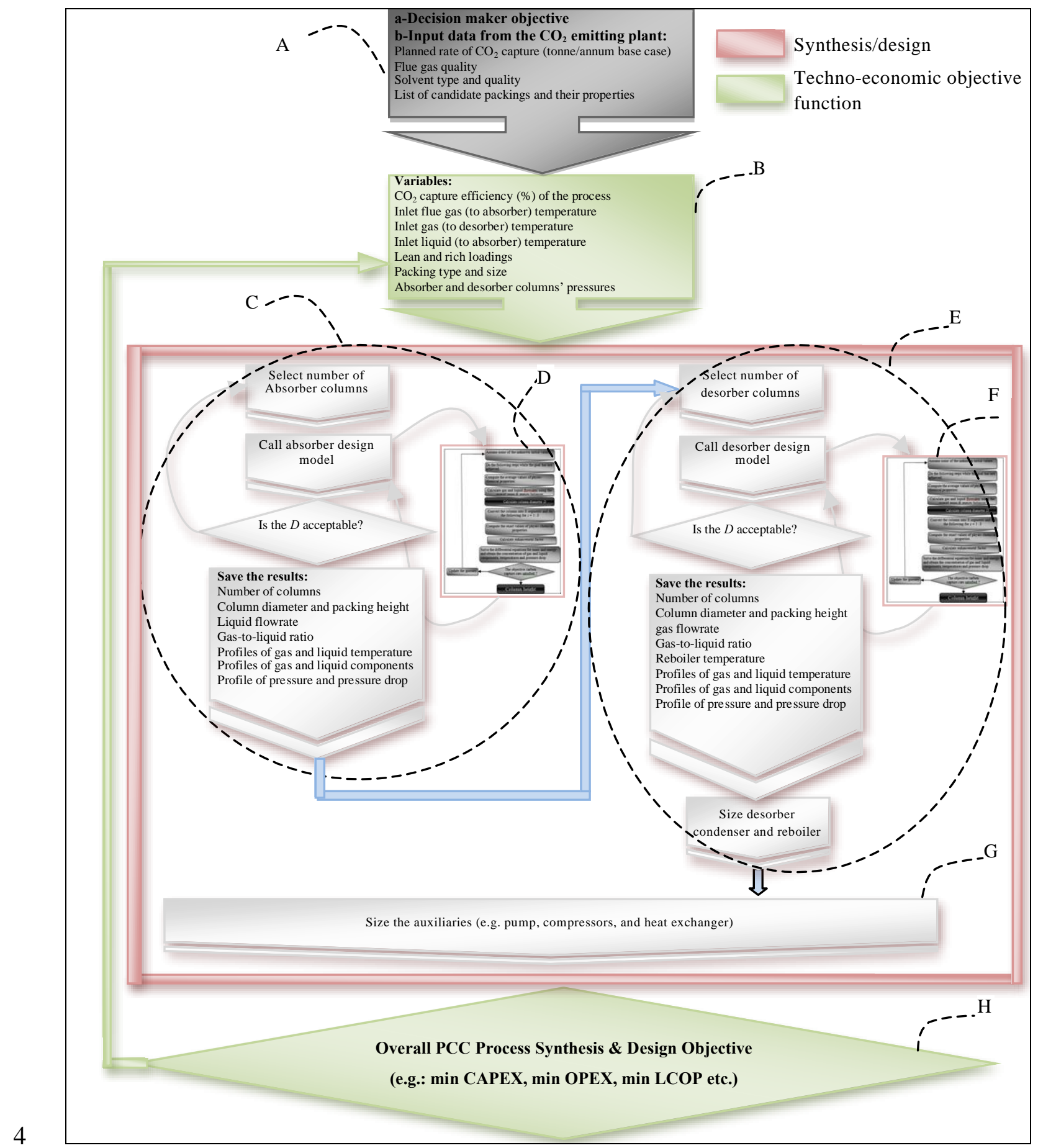

Figure 2: Overall PCC process synthesis and design methodology 


\section{3. Problem formulation}

\section{3.1. Objective function formulation}

3 Here, we present a techno-economic optimisation algorithm for Sol-PCC process system synthesis, design and operation. The manufacturer supplies equipment cost as a function of size, operating conditions, and material quality. There are several cost models specific for any equipment. There are also some generic cost formulations which could be found in process design handbooks and textbooks. Here we use one of the most popular cost functions introduced by Turton et al. (2008) and provided in CAPCOST software package.

9 The purchased cost of equipment at manufacturer's site, including free-on-board (FOB) costs, as 10 given by,

$$
C_{p}=C_{p}^{0} F_{P} F_{M}
$$

12 where, $C_{p}^{0}$ is a base equipment cost, $F_{P}$ is cost factor for pressure and $F_{M}$ is cost factor for material.

13 The base equipment cost, $C_{p}^{0}$ is given by,

$$
\log _{10} C_{p}^{0}=K_{1}+K_{2} \log _{10} X+K_{3}\left[\log _{10} X\right]^{2} \quad X^{\min } \leq X \leq X^{\max }
$$

16 where $X$ is area or volume of the equipment and $K_{1}-K_{3}$ are constants specific for given 17 equipment. A similar correlation is given for the pressure factor, $F_{P}$ and expressed as,

$$
\log _{10} F_{P}=C_{1}+C_{2} \log _{10} P+C_{3}\left[\log _{10} P\right]^{2} \quad P^{\min } \leq P \leq P^{\max }
$$

where $P$ is the design pressure and $C_{1}-C_{3}$ are constants specific for given equipment. Similarly, several direct and indirect costs are involved in the installation of purchased equipment. The

21 summation of all costs makes the bare module cost $\left(C_{B M}\right)$. The direct costs are a) purchased cost

22 of equipment at manufacturer's site, b) cost of materials for installation (piping, insulation and

23 fireproofing, foundations and structural supports, instrumentation and electrical, and painting 24 associated with the equipment), and c) labor costs. The indirect costs include a) freight, insurance, 25 and taxes, b) construction overhead, and c) contractor engineering expenses. For any piece of 26 equipment, the $C_{B M}$ is given by,

$$
C_{B M}=C_{p}^{0} F_{B M}=C_{p}^{0}\left(B_{1}+B_{2} F_{M} F_{P}\right)
$$

28 where $B_{1}$ and $B_{2}$ are constants. Thus, the base bare module cost can be calculated using, 


$$
C_{B M}^{0}=C_{p}^{0} F_{B M}^{0}=C_{p}^{0}\left(B_{1}+B_{2}\right)
$$

2 There is also a third category of costs in the development of a plant which include contingency

$3\left(C_{C o n}=\alpha_{1} \sum C_{B M}\right)$ and contractor fees $\left(C_{C F}=\alpha_{2} \sum C_{B M}\right)$. These costs are calculated as fraction

4 of total bare module costs with constants $\alpha_{1}$ and $\alpha_{2}$. The total module cost $\left(C_{T M}\right)$ is given by,

$5 \quad C_{T M}=\left(1+\alpha_{1}+\alpha_{2}\right) \sum C_{B M}$

6 When a new plant is being planned, there will be a fourth category of costs including site 7 development, auxiliary buildings, off-sites, and utilities. These costs are calculated as a fraction of 8 base bare module cost $\left(C_{A u x}=\alpha_{3} \sum C_{B M}^{0}\right)$. Hence, the fixed capital investment (FCI) costs are 9 given by,

$$
C_{F C I}=C_{T M}+\alpha_{3} \sum C_{B M}^{0}
$$

11 Any new plant also needs a working capital $\left(C_{w c}\right)$ which is a fraction $\left(\alpha_{4}\right)$ of total module costs.

12 Equation (8) concludes the total capital costs, TCI, or CAPEX formulation,

$$
C_{T C I}=C_{F C I}+C_{w c}=\left(1+\alpha_{1}+\alpha_{2}+\alpha_{4}\right) \sum C_{B M}+\alpha_{3} \sum C_{B M}^{0}
$$

Table 2 shows a summary of the total capital expenditure functions.

The operating expenditures (OPEX) consist of two segments including manufacturing costs and general expenses. Manufacturing costs include variable costs (all utilities, maintenance, and repairs, operating labor, operating supplies, supervision, laboratory charges, etc.) and fixed costs (depreciation, property taxes, insurances, and rent). The general expenses include administrative expenses, and distribution and marketing costs (when relevant). A detailed OPEX framework is given elsewhere (Abu-Zahra et al., 2007; Peters et al., 2003). OPEX can also be represented by two components, which are fixed and variable operation and maintenance costs (FOM and VOM).

23 The FOM costs comprise of constant elements such as property insurance, maintenance, repairs, 24 operating labor, supervision, administrative, and R\&D. The annual FOM is usually presented as a 25 fraction of fixed capital investment $\left(F O M_{y}=\beta \times C_{F C I}\right)$. The VOM includes all variable costs 26 such as heating and cooling duties, solvent make-up, as well as the electricity for pumps and 27 compressors. In essence, the annual OPEX could be rearranged and shown by correlation (9) as a summation of FOM and all variable costs,

$$
O X_{y}=F O M_{y}+V O M_{y}=\beta \times C_{F C I}+\sum V O M
$$


Table 2: The total capital expenditure formulation (Turton et al., 2008)

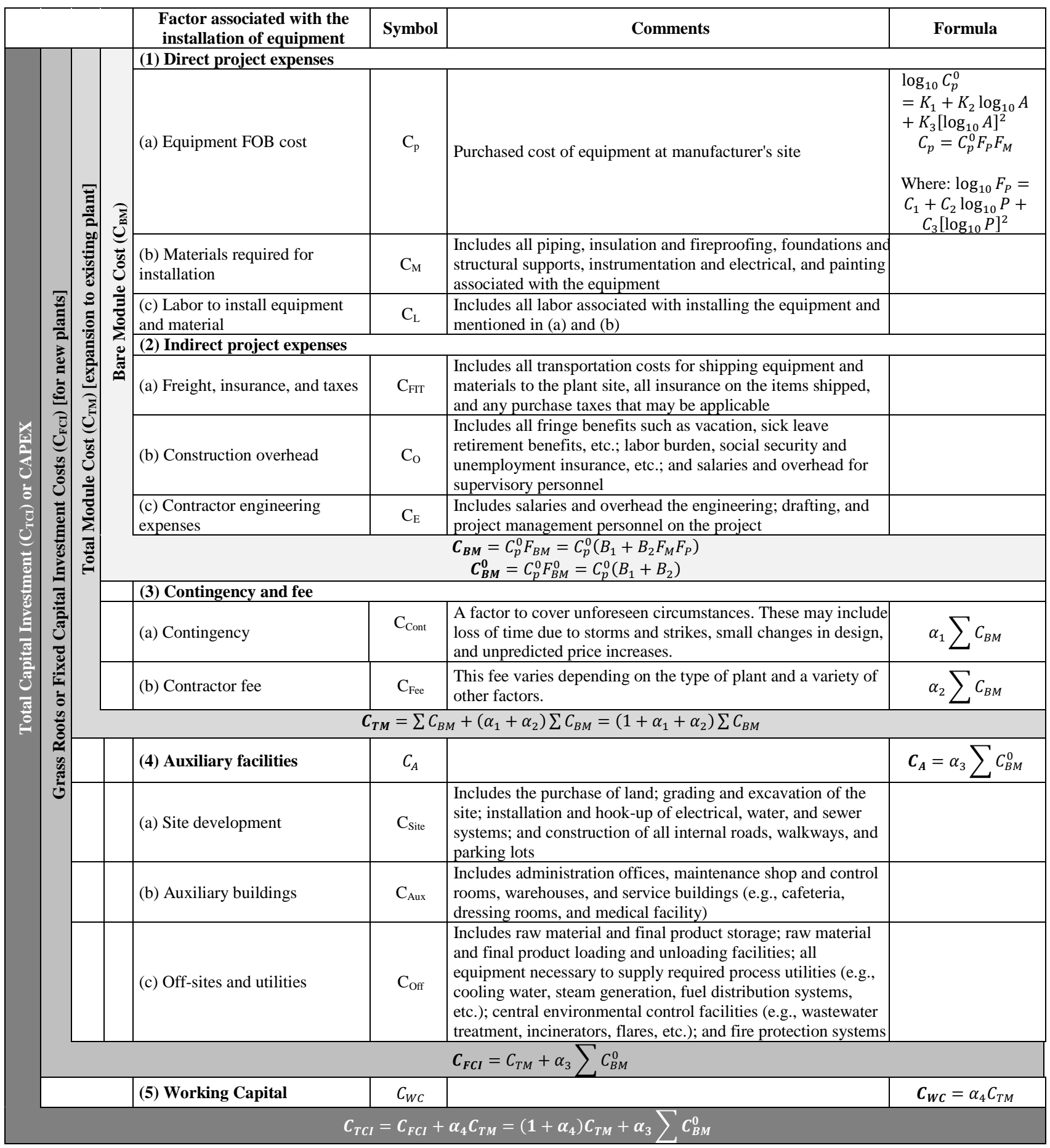


1 As CAPEX and OPEX are the main components of the most techno-economic analysis, we are

2 now able to formulate most types of objective functions. The net present value (NPV) of costs over

3 the planning horizon, as given by,

$4 \quad N P V=C_{T C I}+\sum_{y=1}^{Y} \frac{O X_{y}}{(1+r)^{y}}$

5 in which $O X_{y}$ is the OPEX of the PCC plant during year $y$ and $r$ is a discount rate. LCOP as a

6 levelized cost of energy, as given by,

$$
L C O P=\frac{F C F \times C_{T C X}+O X_{1}}{D C \times T P Y \times C F}
$$

8 where $D C$ is the design capacity of the PCC process in terms of unit weight of $\mathrm{CO}_{2}$ captured per

9 time interval $\Delta t, T P Y$ is the number of $\Delta t$ within a year, and $C F$ is the annual capacity factor of 10 the plant. FCF is the fixed charge factor for levelization of total CAPEX and given by,

$11 \quad F C F=\frac{r(1+r)^{Y}}{(1+r)^{Y}-1}$

12 Therefore, the user can select various objective functions including the ones introduced here, i.e.,

13 CAPEX $\left(C_{T C I}\right)$, OPEX $\left(O X_{y}\right), \mathrm{NPV}$, and LCOP.

\section{3.2. Equipment sizing}

\section{$16 \quad$ 3.2.1. Auxiliary equipment}

17 This stage includes finding the number of units and their corresponding sizes for the absorber,

18 desorber, and all other unit operations. While the generic Sol-PCC process has a schematic similar

19 to Figure 1, the process synthesis and design are a much more complex task as the number of units

20 and their specific sizes are not known. The Sol-PCC process includes the following units:

21 - Flue gas blower

22 - Absorber (might require more than one), with packing and demister

23 - Desorber (might require more than one), with packing and demister, condenser, and drum

24 - Lean/rich heat exchanger

25 - Lean cooling heat exchanger

26 - Lean pump

27 - Rich pump 
- $\mathrm{CO}_{2}$ compression unit (may need more than one unit), each unit requires a compressor, cooling heat-exchanger, and a knock-out drum (with a demister)

3 For each of the mentioned systems, we need their governing design and operational functions. We

4 start first with flue gas blower. The baseline flue gas flowrate is $F_{b}^{F G}$. Therefore, the Sol-PCC

5 process can be designed based on the flue gas flow rate of $F^{F G}$ expressed by,

$$
F^{F G} \leq F_{b}^{F G}
$$

7 Flue gas with a flowrate of $F^{F G}$ enters the blower(s). As the available blowers have minimum and 8 maximum size ranges, there might be a need for one or more blower(s). We define integer variable $9 x^{B}$ as the number of blower with inlet flowrate of $F^{B}$ expressed by,

$$
F_{\text {min }}^{B} \leq F^{B} \leq F_{\text {max }}^{B}
$$

11 and

$$
x^{B} F^{B}=F^{F G}
$$

13 The energy used for the compression of $F^{B}$ from pressure of $P^{F G}$ to absorber inlet pressure $P_{i n}^{A b s}$, 14 as given by,

$$
E^{B}=\frac{F^{B}}{\eta^{B}} \frac{Z^{F G} R T^{F G}}{M^{F G}} \frac{k^{F G}}{k^{F G}-1}\left[\left(\frac{P_{i n}^{F G, A b s}}{P^{F G, B}}\right)^{\frac{k^{F G}-1}{k^{F G}}}-1\right]
$$

16 where, $\eta^{B}$ is the blower efficiency, $R$ is gas constant, and $M^{F G}$ is flue gas molecular weight. $z^{F G}$ 17 and $k^{F G}$ are average flue gas compressibility factor and polytropic constant, respectively, for the 18 operating conditions of the blower. The flue gas, after blower, enters absorber column with 19 pressure and temperature of $P_{i n}^{F G, A b s}$ and $T_{i n}^{F G, A b s}$. Undoubtedly, absorber and desorber design 20 account for the major CAPEX and OPEX of a Sol-PCC system. These two units are also one of 21 the most complex systems due to their reactive-separation processes. The detailed rate-based 22 models of packed-bed absorber and desorber are given elsewhere (Khalilpour and Abbas, 2014a) 23 and a summary of the governing equations are provided as a supplementary document. Here, we 24 keep the focus on discussion about general sizing constraints. The critical step in absorber 25 operation and sizing is the diameter and height of the packing concerning the operating conditions 26 of the inlet gas and lean solvent. Generally, there are limitations for absorber diameter and height 
1 due to operability issues. As such, the optimal process synthesis may require one or more absorber

2 column(s). We define integer variable $x^{A b s}$ as the number of absorber columns with inlet flowrate

3 of $F_{i n}^{A b s}$, where expressed by,

$4 \quad x^{A b s} F_{i n}^{A b s}=F^{F G}$

5 The height of the absorber column has a constant relation with the packing height

$6\left(H^{A b s}=\alpha_{5} H_{\text {pack }}^{A b s}\right)$. The manufacturer constraints on column diameter and packing heights are

7 given by,

$$
H_{\text {min }}^{\text {Abs,pack }} \leq H_{\text {pack }}^{A b s} \leq H_{\text {max }}^{\text {Abs,pack }}
$$

$$
D_{\text {min }}^{A b s} \leq D^{A b s} \leq D_{\text {max }}^{A b s}
$$

10 The demister area $\left(A^{\text {Dem }}\right)$ and packing volumes $\left(V^{\text {pack }}\right)$ for each absorber columns are therefore 11 given calculated using $D^{A b s}$ and $H_{\text {pack }}^{\text {Abs }}$.

12 The flue gas leaves the absorber with $F_{\text {out }}^{F G, A b s}$ and $T_{\text {out }}^{F G, A b s}$ and $P_{\text {out }}^{F G, A b s}$ and a composition defined 13 from of the model is provided in the supplementary document. The flue gas is vented to the 14 atmosphere. The lean solvent entering the top of absorber at the condition $F_{i n}^{L, A b s}, T_{i n}^{L, A b s}, P_{i n}^{L, A b s}$ 15 and $\alpha_{\text {in }}^{L, A b s}$ leaves the column with $F_{\text {out }}^{R, A b s}, T_{\text {out }}^{R, A b s}, P_{\text {out }}^{R, A b s}$ and $\alpha_{\text {out }}^{R, A b s}$. The now-rich solvent is 16 pumped to the pressure of the desorber column (plus the pressure drop within the lean-rich heat 17 exchanger). Occasionally, solvent makeup $\left(F^{M U}\right)$ is also injected to this flow to compensate for 18 losses. The power needed for solvent pumping is $E^{R . P}$. If this power is higher than the maximum 19 capacity of chosen pumps, more than one pump will be needed. We define integer variable $x^{R . P}$ 20 as the number of rich pumps with inlet flowrate of $F^{R . P}$ expressed by,

$$
x^{A b s} F_{i n}^{L, A b s}=x^{R . P} F^{R . P}
$$

22 The energy consumption of each pump, given by,

$$
E^{R . P}=\frac{F^{R . P}\left(P_{\text {in }}^{R, D e s}+\Delta P^{L . R, H X}-P_{\text {out }}^{L, A b s}\right)}{\eta^{R . P}}
$$

24 The rich solvent after passing through the rich-lean heat exchanger enters the desorber column(s) 25 at $T_{i n}^{R, D e s}, P_{i n}^{R, D e s} T_{i n}^{R, D e s}$ and $\alpha_{i n}^{R, D e s}$. The desorber has a complex physico-chemical rate-based heat 26 and mass transfer. The detailed model is provided in the supplementary document. We define 
1 integer variable $x^{\text {Des }}$ as the number of desorber columns with inlet rich flowrate of $F_{\text {in }}^{R \text {,Des }}$, where

2 expressed by,

$3 \quad x^{\text {Des }} F_{\text {in }}^{R, D e s}=x^{R . P} F^{R . P}$

4 The height of the desorber column has a constant relation with the packing height

$5 \quad\left(H^{\text {Des }}=\alpha_{\text {Des }} H_{\text {pack }}^{\text {Des }}\right)$. The manufacturer constraints on column and packing heights are given by,

$6 \quad H_{\text {min }}^{\text {Des,pack }} \leq H_{\text {pack }}^{\text {Abs }} \leq H_{\text {max }}^{\text {Des,pack }}$

$7 \quad D_{\min }^{\text {Des }} \leq D^{\text {Des }} \leq D_{\max }^{\text {Des }}$

8 The demister area and packing volumes for each absorber columns are then given by,

$$
A^{\text {Dem,Des }}=\pi\left(D^{\text {Des }}\right)^{2}
$$

$$
V^{\text {pack,Des }}=\pi\left(D^{\text {Des }}\right)^{2} H_{\text {pack }}^{\text {Des }} / 4
$$

11 The outlet gas with high $\mathrm{CO}_{2}$ concentration goes to a heat exchanger to be water-cooled. The 12 condensed water returns to knock-out drum and recycles to the column for water-washing the 13 exiting gas. The almost-regenerated solvent from the bottom goes to a reboiler where it is heated 14 to the saturation temperature and becomes a two-phase stream. The vapor phase flows upward to 15 the column as stripping gas. The liquid phase, now-called lean solvent, leaves the reboiler with $16 F_{\text {out }}^{L, \text { Des }}, T_{\text {out }}^{L, \text { Des }}, P_{\text {out }}^{L, \text { Des }}$ and $\alpha_{\text {out }}^{L, \text { Des }}$. This hot lean stream goes through the lean-rich heat exchanger

17 (LRHX) and passes its heat to the rich solvent coming from absorber(s).

18 The lean-rich heat exchanger is of shell-and-tube type. The heat exchanger design is based on the 19 interactivity between heat-exchanger area, fluid flow rate, pressure drop and the temperature 20 approach. A low-temperature approach requires a larger heat transfer area where the opposite 21 implies higher thermal duty. Key governing equations are given by,

$$
Q^{R}=\left(x^{A b s} F_{\text {out }}^{R, A b s}\right) C p^{R, L R H X}\left(T_{\text {in }}^{R, D e s}-T_{\text {out }}^{R, A b s}\right)
$$

$$
Q^{L}=\left(x^{\text {Des }} F_{\text {out }}^{L, \text { Des }}\right) C p^{L, L R H X}\left(T_{\text {out }}^{L, \text { Des }}-T_{\text {out }}^{L, L R H X}\right)
$$

24 where, $Q^{R}=Q^{L}=U^{L R H X} A^{L R H X} F^{L R H X} L M T D^{L R H X}$, in which the log mean temperature difference 25 (LMTD) is given by, 


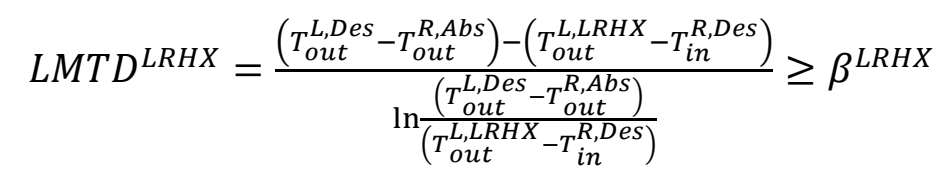

2 where $\beta^{L R H X}$ is a minimum acceptable temperature approach. Given the limitation of heat 3 exchanger sizes, one or more heat exchangers might be needed; hence, we define an integer 4 variable $x^{L R H X}$ as the number of lean-rich heat exchanger size, as expressed by,

$5 \quad A_{\min }^{L R H X} \leq A_{x}^{L R H X} \leq A_{\max }^{L R H X}$

6 and,

$$
A^{L R H X}=x^{L R H X} A_{x}^{L R H X}
$$

8 These constraints will identify the exit temperature of the lean solvent, $T_{\text {out }}^{L, L R H X}$. Evidently, this 9 temperature is greater than the inlet temperature of the absorber, further cooling is required before 10 the lean solvent enters the top of the absorber columns. The duty of lean cooling heat exchanger 11 (LCHX) is given by,

$$
Q^{L C H X}=\left(x^{\text {Des }} F_{\text {out }}^{L, D e s}\right) C p^{L, L C H X}\left(T_{\text {out }}^{L, L R H X}-T_{\text {in }}^{L, A b s}\right)
$$

13 The cooling water enters and leaves at $T_{\text {in }}^{L, c w}$ and $T_{\text {out }}^{L, c w}$. Therefore, we have,

$$
Q^{L C H X}=U^{L C H X} A^{L C H X} F^{L C H X} L M T D^{L C H X}
$$

15 where,

$$
L M T D^{L C H X}=\frac{\left(T_{\text {out }}^{L, L R H X}-T_{\text {in }}^{L, c w}\right)-\left(T_{\text {in }}^{L, A b s}-T_{\text {out }}^{L, c w}\right)}{\ln \frac{\left(T_{\text {out }}^{L, L R H X}-T_{\text {in }}^{L, c w}\right)}{\left(T_{\text {in }}^{L, A b s}-T_{\text {out }}^{L, c w}\right)}} \geq \beta^{L C H X}
$$

17 and $\beta^{L C H X}$ is a minimum acceptable temperature approach. Given the limitations concerning heat 18 exchanger sizes, one or more heat exchangers might be needed, we define an integer variable $19 x^{L C H X}$ as the number of lean cooling heat exchanger size, as expressed by,

$$
A_{\min }^{L C H X} \leq A_{x}^{L C H X} \leq A_{\max }^{L C H X}
$$

21 and

$$
A^{L C H X}=x^{L C H X} A_{x}^{L C H X}
$$

23 The gas exiting the top of the stripper is mainly $\mathrm{CO}_{2}$ and water. It is therefore cooled to remove 24 the major water fraction. The two-phase cooled stream goes to a reflux drum (with a demister) in 
1 which the liquid stream is returned to the desorber and the gas stream (mainly $\mathrm{CO}_{2}$ ) goes for the

2 compression/liquefaction unit. Depending on the ultimate destination of $\mathrm{CO}_{2}$, one or more stages

3 of compression is required to increase the pressure of the gas from pressure at desorber exit, $P^{D e s}$,

4 to export pressure, $P^{e x p}$. A network of compressors is required since the compression ratio ( $P^{\text {exp }} /$

$5 \quad P^{D e s}$ ) exceeds the ability of a single compressor (having a compressibility factor less than 4 ). It is

6 proven that the optimal compression ratio that minimizes total work is such that each stage has an

7 identical ratio (Finlayson, 2006). This can be generalized for a network of $x^{\text {com }}$ stages of

8 compressors, as expressed by,

9

$$
\frac{p_{1}}{p_{\text {Des }}}=\frac{p_{2}}{p_{1}}=\cdots=\frac{p_{x^{\text {comp }}}}{p_{x^{\text {comp }}-1}}=\left(\frac{p_{x^{\text {comp }}}}{p_{\text {Des }}}\right)^{1 / x^{\text {comp }}}
$$

10 Each compression unit is composed of one scrubber, one compressor, and a so-called intercooler 11 heat exchanger after each compressor to decrease the elevated gas temperature and volume. The 12 compressor works to increase the pressure of gas from $p_{\mathrm{i}-1}$ to $p_{\mathrm{i}}$, as given by,

$$
E_{i}^{C m p}=\frac{p_{i} n_{i}}{\rho_{i}\left(n_{i}-1\right)}\left[\left(\frac{p_{i}}{p_{i-1}}\right)^{\frac{n_{i}-1}{n_{i}}}-1\right]
$$

14 where, $n$ is polytropic index. The gas temperature rises after each compression stage as given by,

$$
\Delta T=\frac{\left(T_{i-1}+273.15\right)}{\eta_{i s}}\left[\left(\frac{p_{i}}{p_{i-1}}\right)^{\frac{n_{i}-1}{n_{i}}}-1\right]
$$

16 Given the cooling water inlet and outlet temperatures, the inter-cooling compressor area is

17 computed. With the cooling gas pressure and temperature, the scrubbers' volume is calculated.

18 With the compressor unit, all auxiliary equipment is sized. All knock-out drums are sized based 19 on the governing equations given in Ludwig's Handbook (Coker, 2011). Having described all unit 20 operations, the total module cost $C_{T M}=\sum C_{B M}$ in Eq. (6) could be given in more details by,

$21 C_{T M}=\sum C_{B M}=x^{A b s} C_{B M}^{A b s}+x^{A b s . D e m} C_{B M}^{A b s . D e m}+x^{\text {Des }} C_{B M}^{\text {Des }}+x^{\text {Des.Dem }} C_{B M}^{\text {Des.Dem }}+$ $x^{\text {Des.Reb }} C_{B M}^{\text {Des.Reb }}+x^{\text {Des.CHX }} C_{B M}^{\text {Des.CHX }}+x^{\text {Des.Ref }} C_{B M}^{\text {Des.Ref }}+x^{\text {Blow }} C_{B M}^{\text {Blow }}+x^{\text {R.P }} C_{B M}^{R . P}+$

$$
x^{L R H X} C_{B M}^{L R H X}+x^{L C H X} C_{B M}^{L C H X}+x^{R . P} C_{B M}^{R . P}+\sum_{i=1}^{x^{C o m}}\left(C_{B M, i}^{C o m p}+C_{B M, i}^{I n C H X}+C_{B M, i}^{S c r u b}\right)
$$


The $\sum V O M$ in Eq. (9) is also obtained by summation of all variable operating cost, as given by,

$$
\begin{gathered}
V O M_{y}=T P Y \sum V O M=T P Y\left[E E P_{y}\left(x^{B} E^{B}+x^{R . P} E^{R . P}+\sum_{i=1}^{x^{C o m}} E_{i}^{C o m}\right)+\right. \\
\left.H E P_{y}\left(x^{D e s} Q^{\text {Reb }}\right)+C E P_{y}\left(x^{L C H X} Q^{L C H X}+x^{D e s} Q^{\text {Des.CHX }}+\sum_{i=1}^{x^{C o m}} Q_{i}^{\text {IntCHX }}\right)+S P_{y} F^{M U}\right]
\end{gathered}
$$

This completes our sizing formulation.

\subsection{Problem execution}

The structure of this problem solution is illustrated in Figure 2. Given the complex nature of absorber and desorbed processes, we have found heuristic algorithms (such as evolutionary algorithms) the most reliable solution approach. Once, the input parameters are supplied (A in Figure 2), the program initiates with the selection of a set of random values for the direct variables (No 1-9 in Table 1 or section $B$ in Figure 2). With this, the process design initiates; the specifications of absorber (sections C-D in Figure 2) and desorber (sections E-F in Figure 2) are found based on the set of equations supplied in the supplementary file. The specifications of other equipment (sections $G$ in Figure 2) are found using Eqs. (13-40). The program then calculates the objective function values using relevant Eqs. (1-12) and (39-40). Having obtained the objective value, a new set of random values are generated for the direct variables (B in Figure 2), and the execution is repeated until the program converges in the optimal value. In this study, we have used Matlab $^{\oplus} 2014 b$, though any open-source or proprietary programming software environment can be employed.

\section{Case study}

A 300 MW coal-fired power plant in Australia typically burns pulverized black coal with 25\% ash, $8 \%$ moisture, and dry-ash-free (DAF) with the chemical composition of $83.3 \%$ carbon, $5.4 \%$ hydrogen, $1.9 \%$ nitrogen, $0.6 \%$ sulfur, and $8.8 \%$ oxygen. The power plant emits $12260 \mathrm{~mol} / \mathrm{s}$ $(353.3 \mathrm{~kg} / \mathrm{s})$ of flue gas when operating at its full capacity. The flue gas composition is $13.0 \mathrm{vol} \%$ (19.8 wt $\%$ ) $\mathrm{CO}_{2}, 70.37 \% \mathrm{~N}_{2}, 13.52 \% \mathrm{H}_{2} \mathrm{O}, 3.11 \% \mathrm{O}_{2}$ and ppm levels of $\mathrm{SO}_{\mathrm{X}}$ and $\mathrm{NO}_{\mathrm{x}}$. The $\mathrm{SOx}$ and NOx are removed from the flue gas before venting or entering the PCC process. When operated in the full capacity, the plant emits 2.2 million tonnes of $\mathrm{CO}_{2}$ per annum. The company desires to investigate the feasibility of investment in a Sol-PCC process which can annually capture $\geq 75 \%$ of its $\mathrm{CO}_{2}$ emission when operating at a capacity factor of $85 \%$. The preferred solvent is 
1 MEA due to the minimum commercial risks. The optimum operating temperature of an MEA 2 absorber is commonly in a range of $40-60{ }^{\circ} \mathrm{C}$; hence, the temperature of flue gas requires to be 3 adjusted to the range of absorber operating conditions before entering the absorber. The 4 physicochemical properties (viscosities, densities, thermal conductivities, surface tensions, the 5 heat of reaction, diffusivities, specific heat, mass, and heat transfer coefficients) of the MEA solvents used in this modeling/design work are explained and presented in (Khalilpour and Abbas, 2014b). The techno-economic parameters for equipment bare module cost calculations are given in Table 3. The maximum allowable column diameter and packing heights are $12 \mathrm{~m}$ and $25 \mathrm{~m}$, respectively. The captured $\mathrm{CO}_{2}$ is aimed to be compressed to 100 bars, cooled to $50{ }^{\circ} \mathrm{C}$; and subsequently exported for the planned applications (sequestration, utilization, etc.).

Table 3: The optimal operational and design variables with two objective functions (Turton et al., 2008).

\begin{tabular}{|c|c|c|c|c|c|c|c|c|c|}
\hline \multirow[t]{2}{*}{ Equipment } & \multicolumn{3}{|c|}{$\begin{array}{l}\log _{10} C_{p}^{0} \\
=K_{1}+K_{2} \log _{10} X \\
+K_{3}\left[\log _{10} X\right]^{2} \\
\end{array}$} & \multicolumn{3}{|c|}{$\boldsymbol{F}_{P}$} & \multicolumn{3}{|c|}{$F_{B M}=B_{1}+B_{2} F_{M} F_{P}$} \\
\hline & $\mathbf{K}_{1}$ & $\mathbf{K}_{2}$ & $\mathbf{K}_{3}$ & $\mathbf{C}_{1}$ & $\mathbf{C}_{2}$ & $\mathbf{C}_{3}$ & $\mathbf{B}_{1}$ & $\mathbf{B}_{2}$ & $\mathbf{F}_{\mathbf{M}}$ \\
\hline Blower (Centrifugal Radial Fan) & 3.54 & -0.35 & 0.45 & 0.00 & 0.21 & -0.03 & \multicolumn{3}{|c|}{$2.74(\mathrm{CS})$} \\
\hline Columns (vertical vessel) & 3.50 & 0.45 & 0.11 & \multicolumn{3}{|c|}{$\frac{\frac{P D}{50-0.6 P]}+0.00315}{0.0063}$} & 2.25 & 1.82 & $3.10(\mathrm{SS})$ \\
\hline $\begin{array}{l}\text { Packing (ceramic) } \\
\text { absorber/desorber }\end{array}$ & 3.07 & 0.97 & 0.01 & - & - & - & \multicolumn{3}{|c|}{4.20} \\
\hline $\begin{array}{l}\text { Demister (absorber, desorber, } \\
\text { knock-out drums) }\end{array}$ & 3.24 & 0.48 & 0.34 & \multicolumn{6}{|c|}{$F_{B M}=1.00(\mathrm{SS})$} \\
\hline Rich solvent pump (Centrifugal) & 3.39 & 0.05 & 0.15 & -0.39 & 0.40 & -0.00 & 1.89 & 1.35 & $2.30(\mathrm{SS})$ \\
\hline Compressor (centrifugal) & 2.29 & 1.36 & -0.10 & \multicolumn{6}{|c|}{$F_{B M}=5.80(\mathrm{SS})$} \\
\hline Compressor electric drive & 2.46 & 1.42 & -0.18 & \multicolumn{6}{|c|}{$F_{B M}=1.50$} \\
\hline Reflux drum horizontal & 3.56 & 0.38 & 0.09 & \multicolumn{3}{|c|}{$F_{P}=\frac{\frac{P D}{2[850-0.6 P]}+0.00315}{0.0063}$} & 1.49 & 1.52 & $2.3(\mathrm{SS})$ \\
\hline Shell and Tube HX & 4.32 & -0.30 & 0.16 & 0.04 & -0.11 & 0.08 & 1.63 & 1.66 & $2.73(\mathrm{SS} / \mathrm{SS})$ \\
\hline Kettle reboiler & 4.47 & -0.53 & 0.40 & 0.04 & -0.11 & 0.08 & 1.63 & 1.66 & $2.73(\mathrm{SS} / \mathrm{SS})$ \\
\hline
\end{tabular}

13 The fixed and variable operating cost parameters are given in Table 4. The Chemical Engineering

14 Plant Cost Index (CEPCI) is used to convert the economic values to 2016 dollar (index: 541.7). It

15 is noteworthy to clarify that we use electricity price to calculate the reboiler energy. This is because

16 the steam which is used to heat the reboiler is extracted from power plant turbines aimed for 17 electricity generation. In this study, we have assumed that one Joule of reboiler energy equals to 180.19 Joule of electricity, i.e., $H E P=0.19 E E P$ (Khalilpour and Abbas, 2011). The minimum 19 acceptable temperature approach is $3{ }^{\circ} \mathrm{C}$ for the kettle reboiler and $5{ }^{\circ} \mathrm{C}$ for all other heat 20 exchangers. 
1 The company desires to assess two different scenarios. In scenario (i), the objective is to design 2 the plant with minimum possible total capital investment. In scenario (ii), the objective is to design 3 the plant to minimize the levelized costs per unit weight of captured $\mathrm{CO}_{2}$. The planning horizon is 425 years with a constant discount rate of $10 \%$, and an inflation rate of $3 \%$.

Table 4: Economic parameters (annual basis unless otherwise the unit is mentioned).

\begin{tabular}{l|l|l}
\hline Manufacturing cost & Range & Values for this study \\
\hline Fixed charge & & \\
\hline Property Insurance & $1 \%$ of FCI & 1 \\
\hline Variable production cost & & \\
\hline Utilities & according to optimisation results & \\
\hline MEA makeup & $1.5 \mathrm{~kg} /$ tonne-CO 2 -captured & \\
\hline Maintenance and repairs & $1-10 \%$ of FCI & 5 \\
\hline Operating labour & $3 \%$ FCI & 3 \\
\hline Supervision & $15 \%$ of operating a labor & 15 \\
\hline Laboratory charges & $10-20 \%$ of operating a labor & 15 \\
\hline Operating supplies & $15 \%$ of maintenance and repairs & 15 \\
\hline Plant overhead cost & $50-70 \%$ of (maintenance + operating + & 60 \\
\hline General expenses & labour + supervision) & \\
\hline Administrative cost & $15-25 \%$ of (maintenance + operating + & 20 \\
\hline R\&D cost & labour + supervision) & \\
\hline Utilities & $0.5 \%$ FCI & 0.5 \\
\hline Electricity $(110-440 \mathrm{~V})$ & & 49.36 \$2016/MWh \\
\hline Cooling water $\left(30-45^{\circ} \mathrm{C}\right)$ & & $\begin{array}{l}\text { NEM, Australia) } \\
\text { (Turton et al., 2009) }\end{array}$ \\
\hline
\end{tabular}

7 Table 5 shows the results of the optimization for the two required objective functions. The program can find the optimal values of both technical (design and operational) and economic variables.

9 Under the CAPEX optimization (scenario i), the program synthesizes a PCC plant with two 10 absorber columns (Diameter: $10.54 \mathrm{~m}$, packing height: $13.20 \mathrm{~m}$ ) and one desorber column 11 (Diameter: $11.27 \mathrm{~m}$, Packing height: $14.60 \mathrm{~m}$ ). The optimal reboiler duty of the desorber is found 12 as $4.87 \mathrm{GJ} /$ tonne- $\mathrm{CO}_{2}$. The minimum CAPEX is evaluated as $\$ 312.36$ million. The levelized cost 13 of $\mathrm{CO}_{2}$ capture and compression, under this scenario, is found to be $58.07 \$ /$ tonne- $\mathrm{CO}_{2}$.

14 The carbon capture levelized cost under scenario (ii) is a combination of both CAPEX and OPEX.

15 The ideal process combination under this scenario is similar to the CAPEX scenario, i.e., two 16 absorber columns and one desorber column. However, the corresponding values of techno17 economic variables are different in this scenario. Absorber columns have a diameter of $10.52 \mathrm{~m}$ 
1 and packing height of $18.20 \mathrm{~m}$. The diameter of desorber column is $9.68 \mathrm{~m}$ with packing height 2 being $18.90 \mathrm{~m}$.

3 The absorber and desorber columns are deemed to be larger than those for the previous scenario.

4 The reason for scenario (i) having shorter absorber and desorber columns lies in the fact that 5 installation cost is directly linked with column height. The lower, the column height, the lower 6 will be the ultimate CAPEX. However, lower columns lead to increased operating costs. As 7 scenario (i), does not include operating costs, the lowest CAPEX is achieved by using short 8 columns and passing all subsequences on the operating costs. However, the objective function of 9 scenario (ii) concurrently considers minimization of both CAPEX and OPEX. As such, though it 10 leads to larger column heights than scenario (i), its reboiler duty is considerably low, (2.5 GJ/tonne$11 \mathrm{CO}_{2}$ vs $4.87 \mathrm{GJ} /$ tonne- $\mathrm{CO}_{2}$ in the previous scenario).

12 The CAPEX, under scenario (ii), is around $\$ 12.82$ million higher than the previous scenario 13 (\$325.18 million vs. \$312.36 million). Nonetheless, the minimum levelized cost is found to be $1452.82 \$ /$ tonne- $\mathrm{CO}_{2}$ which is $5.25 \$ /$ tonne- $\mathrm{CO}_{2}$ lower than the scenario one. The schematic of the 15 process within the scenario two is illustrated Figure 3. This example demonstrates the design and 16 operational interactivity, and how the plant design can essentially change with different project's 17 objectives. It is also highlighting that the optimal design can vary depending on the local economic 18 input parameters and desires.

Table 5: The optimal operational and design variables with two objective functions.

\begin{tabular}{|c|c|c|c|}
\hline & Objective & $\begin{array}{l}\text { Scenario (i): } \\
\text { Min. CAPEX }\end{array}$ & $\begin{array}{c}\text { Scenario (ii): } \\
\text { Min. levelized capture cost }\end{array}$ \\
\hline \multirow{19}{*}{ 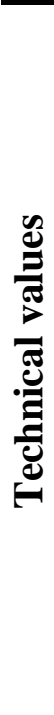 } & Blower (No. units), [flowrate/unit, $\mathrm{m}^{3} / \mathrm{s}$ ], [power/unit, MW] & $(2),[157.80],[3.02]$ & $(2),[157.80],[3.02]$ \\
\hline & Absorber & & \\
\hline & Number of columns & 2 & 2 \\
\hline & Column diameter $(\mathrm{m})$ & 10.54 & 10.52 \\
\hline & Packing height $(\mathrm{m})$ & 13.20 & 18.20 \\
\hline & Packing type & Berl saddle $50 \mathrm{~mm}$ & Berl saddle $50 \mathrm{~mm}$ \\
\hline & Demister size $\left(\mathrm{m}^{2}\right)$ & 87.20 & 86.90 \\
\hline & Desorber & & \\
\hline & Number of columns & 1 & 1 \\
\hline & Column diameter $(\mathrm{m})$ & 11.27 & 9.68 \\
\hline & Packing height $(\mathrm{m})$ & 14.60 & 18.90 \\
\hline & Packing type & Berl saddle $50 \mathrm{~mm}$ & Berl saddle $50 \mathrm{~mm}$ \\
\hline & Demister area & 99.70 & 73.60 \\
\hline & Condenser area $\left(\mathrm{m}^{2}\right)$ & 2107.30 & 1859.90 \\
\hline & Reflux drum Diameter (m), height (m) & $4.10,20.97$ & $3.92,23.28$ \\
\hline & Kettle reboiler area $\left(\mathrm{m}^{2}\right)$, and temperature approach $\left({ }^{\circ} \mathrm{C}\right)$ & $17023.11,3.00$ & $8738.76,3.00$ \\
\hline & Compressor and export train & & \\
\hline & Number of compressor stages & 4 & 4 \\
\hline & Pressure rations & 2.80 & 2.80 \\
\hline
\end{tabular}




\begin{tabular}{|c|c|c|c|}
\hline & Compressor 1 capacity (MW) & 5.54 & 5.55 \\
\hline & Compressor 2 capacity (MW) & 5.54 & 5.55 \\
\hline & Compressor 3 capacity (MW) & 5.54 & 5.55 \\
\hline & Compressor 4 capacity (MW) & 5.54 & 5.55 \\
\hline & Knock-out drum 1 Diameter (m), height (m) & - & - \\
\hline & Knock-out drum 2 Diameter (m), height (m) & $2.76,12.40$ & $2.76,12.40$ \\
\hline & Knock-out drum 3 Diameter (m), height (m) & $2.13,7.08$ & $2.13,7.08$ \\
\hline & Knock-out drum 4 Diameter (m), height (m) & $1.62,3.65$ & $1.62,3.65$ \\
\hline & Inter-stage cooling HX 1 area $\left(\mathrm{m}^{2}\right)$ & - & - \\
\hline & Inter-stage cooling HX 2 area $\left(\mathrm{m}^{2}\right)$ & 191.32 & 191.32 \\
\hline & Inter-stage cooling HX 3 area $\left(\mathrm{m}^{2}\right)$ & 190.25 & 190.25 \\
\hline & Inter-stage cooling HX 4 area $\left(\mathrm{m}^{2}\right)$ & 200.76 & 200.7 \\
\hline & Final cooling $\mathrm{HX}\left(\operatorname{export} \mathrm{CO}_{2}\right.$ to $\left.50{ }^{\circ} \mathrm{C}\right)$ area $\left(\mathrm{m}^{2}\right)$ & 239.13 & 239.13 \\
\hline & $\begin{array}{l}\text { Lean/rich Heat-exchanger size }\left(\mathrm{m}^{2}\right) \text {, and temperature approach } \\
\left({ }^{\circ} \mathrm{C}\right)\end{array}$ & $17922.04,7.00$ & $17840.95,7.00$ \\
\hline & Lean cooler $\mathrm{HX}$ area $\left(\mathrm{m}^{2}\right)$ & 992.77 & 981.88 \\
\hline \multirow{21}{*}{ 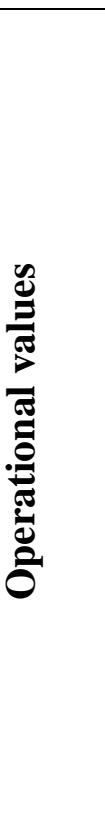 } & $\mathrm{CO}_{2}$ capture efficiency $(\%)$ of the PCC plant & 90.00 & 90.00 \\
\hline & Absorber & & \\
\hline & Temperature of the inlet flue gas to absorber $\left({ }^{\circ} \mathrm{C}\right)$ & 50.00 & 50.00 \\
\hline & Temperature of the inlet solvent to absorber $\left({ }^{\circ} \mathrm{C}\right)$ & 56.62 & 56.89 \\
\hline & Temperature of the outlet solvent from absorber $\left({ }^{\circ} \mathrm{C}\right)$ & 63.00 & 63.00 \\
\hline & Lean loading & 0.25 & 0.30 \\
\hline & Rich loading & 0.40 & 0.45 \\
\hline & Pressures of absorber columns $(\mathrm{kPa})$ & $1.05-1.10$ & $1.02-1.10$ \\
\hline & Pressure drop of absorber column $(\mathrm{s})(\mathrm{kPa})$ & 5.40 & 7.75 \\
\hline & $\mathrm{L}_{\mathrm{mol}} / \mathrm{G}_{\mathrm{mol}}$ & 6.83 & 6.83 \\
\hline & $\mathrm{CO}_{2}$ molar fraction of the emitted flue gas & 0.01 & 0.01 \\
\hline & Desorber & & \\
\hline & \begin{tabular}{|l|l} 
Temperature of the inlet solvent to desorber $\left({ }^{\circ} \mathrm{C}\right)$ \\
\end{tabular} & 107.64 & 107.68 \\
\hline & Temperature of the gas at desorber column exit $\left({ }^{\circ} \mathrm{C}\right)$ & 107.94 & 108.45 \\
\hline & Pressure of desorber columns $(\mathrm{kPa})$ & $1.64-1.70$ & $1.62-1.70$ \\
\hline & Pressure drop of desorber columns $(\mathrm{kPa})$ & 6.46 & 8.09 \\
\hline & $\mathrm{CO}_{2}$ molar fraction of the gas at the top of desorber & 0.21 & 0.39 \\
\hline & $\mathrm{L}_{\mathrm{mol}} / \mathrm{G}_{\mathrm{mol}}$ & 11.22 & 19.85 \\
\hline & Reboiler temperature $\left({ }^{\circ} \mathrm{C}\right)$ & 127 & 127 \\
\hline & Reboiler duty (GJ/tonne-CO $\mathrm{CO}_{2}$ & 4.87 & 2.5 \\
\hline & $\begin{array}{l}\text { Total } \mathrm{CO}_{2} \text { captured annually (million tonnes/y) }\left(\% \text { of } \mathrm{CO}_{2}\right. \\
\text { generation) }\end{array}$ & $1.69(76.8)$ & $1.69(76.8)$ \\
\hline \multirow{5}{*}{ 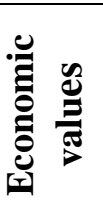 } & FOM (\$million/y) & 23.33 & 23.71 \\
\hline & VOM (\$million/y) & 40.24 & 29.58 \\
\hline & Total OPEX (\$million/y) & 63.57 & 53.29 \\
\hline & Total capital investment (\$million) & $\underline{312.36}$ (objective) & 325.18 \\
\hline & Levelized capture cost (\$/tonne- $\left.\mathrm{CO}_{2}\right)$ & 58.07 & $\underline{\mathbf{5 2 . 8 2}}$ (objective) \\
\hline
\end{tabular}




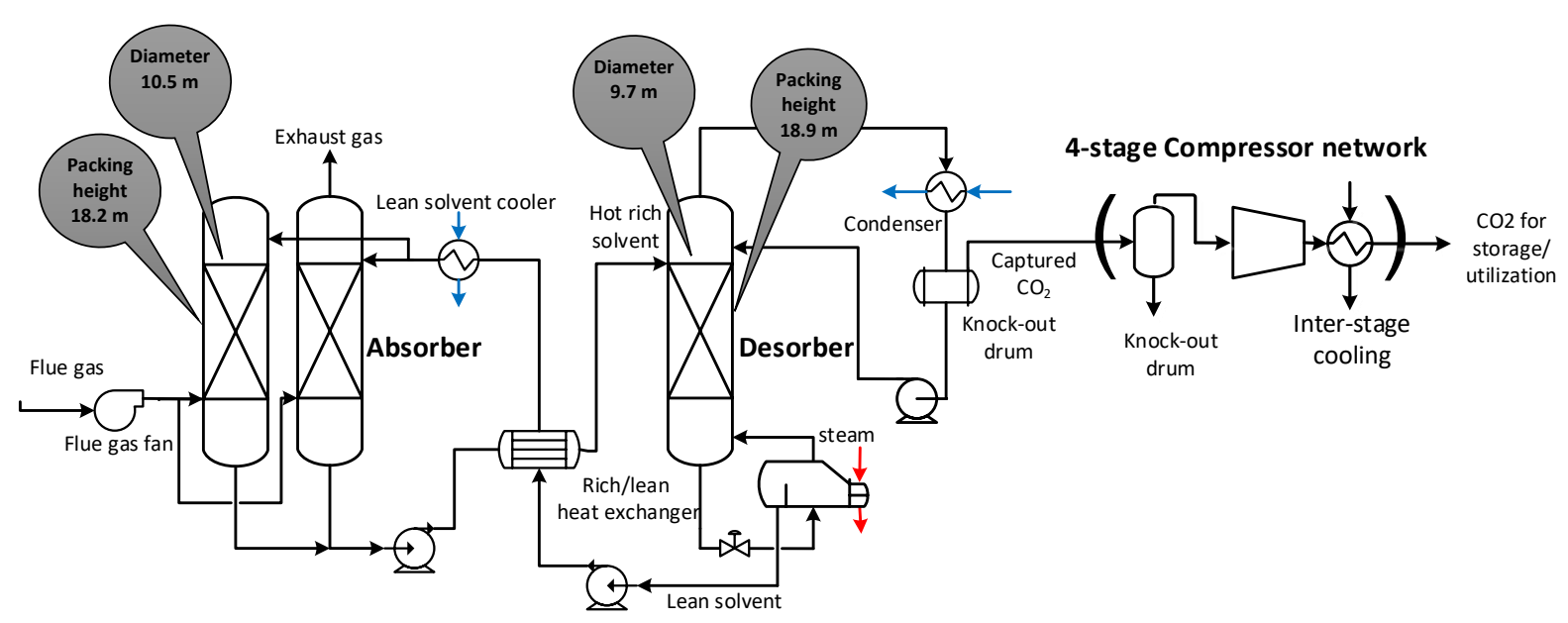

\begin{tabular}{|c|c|c|c|c|c|c|c|c|c|c|c|c|c|c|}
\hline $\begin{array}{c}\text { Rich } \\
\text { loading }\end{array}$ & $\begin{array}{c}\text { Lean } \\
\text { loading }\end{array}$ & \begin{tabular}{|c|}
$T_{i n}^{F G, A b}$ \\
$\left({ }^{\circ} \mathbf{C}\right)$ \\
\end{tabular} & $\begin{array}{c}T_{i n}^{L, A b s} \\
\left({ }^{\circ} \mathrm{C}\right)\end{array}$ & \begin{tabular}{|c|}
$T_{\text {out }}^{F G, A b}$ \\
$\left({ }^{\circ} \mathbf{C}\right)$
\end{tabular} & $\begin{array}{c}T_{\text {out }}^{R, A b s} \\
\left({ }^{\circ} \mathbf{C}\right)\end{array}$ & $\mathbf{y}_{\mathrm{CO} 2 \text {,out }}$ & $\begin{array}{c}\text { D } \\
(\mathbf{m})\end{array}$ & $\begin{array}{c}\mathbf{Z} \\
(\mathbf{m})\end{array}$ & $\begin{array}{c}\mathbf{P}_{\text {out }} \\
\text { (bar) }\end{array}$ & $\begin{array}{c}\Delta \mathbf{P} \\
(\mathbf{k P a})\end{array}$ & $\begin{array}{c}\mathbf{Q}^{\mathbf{L}} \\
\text { (lit/s) }\end{array}$ & $\begin{array}{c}\mathbf{L}_{\mathrm{mol}} \\
(\mathrm{mol} / \mathrm{s})\end{array}$ & $\mathbf{L}_{\mathbf{m o l}} / \mathbf{G}_{\mathbf{m o l}}$ & $\begin{array}{c}\mathbf{Q} \\
\left(\mathrm{MJ} / \mathrm{kg}-\mathrm{CO}_{2}\right)\end{array}$ \\
\hline \multicolumn{15}{|c|}{ Absorber (two units) } \\
\hline 0.45 & 0.30 & 50.0 & 56.9 & 57.0 & 63.0 & 0.01 & 10.5 & 18.2 & 1.1 & 7.75 & 956.2 & 42076.0 & 6.83 & - \\
\hline \multicolumn{15}{|c|}{ Desorber (one unit) } \\
\hline 0.45 & 0.30 & 107.7 & 124 & 108.5 & 118.0 & 0.39 & 9.7 & 18.9 & 1.7 & 8.09 & 1912.4 & 82158.2 & 19.85 & 2.5 \\
\hline
\end{tabular}

Figure 3: Schematic of solvent-based PCC process configuration for a $300 \mathrm{MW}$ coal-fired power plant with the list of optimal design and operation values using minimum levelized capture cost as the objective function.

\section{Conclusion}

10 In this paper, we developed an equation-based methodology to address the uncertainties and

11 variabilities in the techno-economic assessment of integrated Sol-PCC processes. These

12 technologies are undoubtedly complex due to involving reactive separation. Hence, integrating

13 their physico-chemical models with techno-economic design optimisation algorithms adds further

14 to the project complexity. The method developed here is capable of evaluating feasible design

15 variables compatible with economic objectives. This decision-support tool consists of a

16 comprehensive techno-economic approach for finding the right design and operation values.

17 Techno-economic assessments conducted for a $300 \mathrm{MW}$ coal-fired power plant integrated with a

18 Sol-PCC process used to showcase the interactivity between design and operational parameters for

19 two separate practice scopes of i) minimizing total capital investment, and ii) minimizing levelized

20 capture costs. Comparison of the examined scenarios showed that despite $\sim 5 \%$ increase in the total

21 capital investment, the levelized capture costs reduced by $\sim 9 \%$ within the case (ii) which

22 influences a significant difference in running expenditure of the plant over its lifecycle. These

23 results further imply that design and operation variables vary based on different techno-economic 
1 objectives; while each case might be efficient on its own merits, most likely there is no single

2 optimal design exists which can deliver all different objectives at once.

\section{Glossary}

4 Abbreviations

5 CAPEX

6 CEPCI

7 FOB

8 MEA

9 OPEX

\section{Notations}

$13 \mathrm{C}_{\mathrm{BM}}$

$14 \mathrm{C}_{\mathrm{TM}}$

$15 \mathrm{C}_{\mathrm{FCI}}$

$16 \mathrm{C}_{\text {FIT }}$

$17 \quad \mathrm{C}_{\mathrm{TCT}}$

$18 \mathrm{CF}$

$19 \mathrm{CEP}_{y}$

20 FCF

$21 \quad \mathrm{FOM}_{\mathrm{y}}$

22 EEP $y$

$23 \mathrm{HEP}_{y}$

24 IRR

25 LCOP

26 NPV

$27 \quad \mathrm{OX}_{\mathrm{y}}$

$28 \mathrm{r}$

29 T

30 TPY

$31 \quad \mathrm{VOM}_{\mathrm{y}}$

$32 \Delta t$

33

\section{References}

capital expenditure (equivalent to total capital investment, TCI)

Chemical Engineering Plant Cost Index

free on board

monoethanolamine

operational expenditure

fixed CAPEX

bare module cost

total module cost

fix capital investment

freight, insurance, and taxes

total capital investment (equivalent to CAPEX)

annual capacity factor

cooling energy price at year $y$

fixed charge factor

fixed operation and maintenance costs during year $y$

pool price electricity at year $y$

heating energy price at year $y$

initial rate of return

levelized cost of product

net present value

OPEX during year $y$

discount rate

length of the planning horizon

number of periods $(\Delta t)$ within a year

variable operation and maintenance costs during year $y$

time interval

35 Aaron, D., Tsouris, C., 2005. Separation of CO2 from flue gas: A review. Separ Sci Technol 40, 36 321-348.

37 Abu-Zahra, M.R., Niederer, J. P., Feron, P. H., \& Versteeg, G. F., 2007a. $\mathrm{CO}_{2}$ capture from power 38 plants: Part II. A parametric study of the economical performance based on mono-ethanolamine.

39 International journal of greenhouse gas control 1, 135-142.

40 Abu-Zahra, M.R.M., Niederer, J.P.M., Feron, P.H.M., Versteeg, G.F., 2007. CO2 capture from

41 power plants: Part II. A parametric study of the economical performance based on mono-

42 ethanolamine. International Journal of Greenhouse Gas Control 1, 135-142. 
Abu-Zahra, M.R.M., Schneiders, Léon H. J., Niederer, John P. M., Feron, Paul H. M., Versteeg, Geert F.,, 2007b. $\mathrm{CO}_{2}$ capture from power plants: Part I. A parametric study of the technical performance based on monoethanolamine. International Journal of Greenhouse Gas Control 1, 3746.

Astarita, G., 1967. Mass transfer with chemical reaction. Elsevier, Amsterdam, London,. Astarita, G., Savage, David W., Bisio, Attilio., 1983. Gas treating with chemical solvents. John Wiley, New York.

Biliyok, C., Roberto Canepa, Meihong Wang, and Hoi Yeung, 2013. "Techno-economic analysis of a natural gas combined cycle power plant with $\mathrm{CO}_{2}$ capture" Computer aided chemical engineering 32, 187-192.

Coker, A.K., 2011. Ludwig's Applied Process Design for Chemical and Petrochemical Plants. Elsevier Science.

Damartzis, T., Papadopoulos, A.I., Seferlis, P., 2014. Optimum synthesis of solvent-based postcombustion $\mathrm{CO} 2$ capture flowsheets through a generalized modeling framework. Clean Technologies and Environmental Policy 16, 1363-1380.

Damartzis, T., Papadopoulos, A.I., Seferlis, P., 2016. Process flowsheet design optimization for various amine-based solvents in post-combustion $\mathrm{CO} 2$ capture plants. Journal of Cleaner Production 111, 204-216.

Danckwerts, P.V., 1970. Gas-liquid reactions. McGraw-Hill Book Co., New York,.

Danckwerts, P.V., Sharma, M.M., 1966. The absorption of carbon dioxide into aqueous amine solutions of alkalis and amines (with some notes on hydrogen sulphide and carbonyl sulphide). The Chemical Engineer 2, CE244-CE280.

Dave, N., Do, T., Palfreyman, D., Feron, P. H. M., Xu, S., Gao, S., Liu, L.,, 2011. Post-combustion capture of $\mathrm{CO}_{2}$ from coal-fired power plants in China and Australia: An experience based cost comparison. Energy Procedia 4, 1869-1877.

Desideri, U., Paolucci, A., 1999. Performance modelling of a carbon dioxide removal system for power plants. Energ Convers Manage 40, 1899-1915.

Finlayson, B.A., 2006. Introduction to chemical engineering computing. Wiley-Interscience, Hoboken, N.J.

Freguia, S., Rochelle, G.T., 2003. Modeling of $\mathrm{CO}_{2}$ capture by aqueous monoethanolamine. Aiche J 49, 1676-1686.

Herzog, H., Drake, E., Adams, E., 1997. CO2 Capture, Reuse, and Storage Technologies for Mitigating Global Climate Change.

IEA, 2016. Energy Technology Perspectives International Energy Agency

IPCC, 2018. Global Warming of $1.5^{\circ} \mathrm{C}$ : An IPCC Special Report on the Impacts of Global Warming of $1.5^{\circ} \mathrm{C}$ Above Pre-industrial Levels and Related Global Greenhouse Gas Emission Pathways, in the Context of Strengthening the Global Response to the Threat of Climate Change, Sustainable Development, and Efforts to Eradicate Poverty. World Meteorological Organization, Geneva.

Kenig, E.Y., Górak, A., 2005. Reactive Absorption, Integrated Chemical Processes. Wiley-VCH Verlag GmbH \& Co. KGaA, pp. 265-311.

42 Khalilpour, R., 2014. Flexible Operation Scheduling of a Power Plant Integrated with PCC Processes under Market Dynamics. Ind Eng Chem Res 53, 8132-8146.

Khalilpour, R., Abbas, A., 2011. HEN optimization for efficient retrofitting of coal-fired power plants with post-combustion carbon capture. International Journal of Greenhouse Gas Control 5, 46 189-199. 
Khalilpour, R., Abbas, A., 2014a. Optimal synthesis and design of solvent-based PCC process using a rate-based model. Separation and Purification Technology 132, 149-167.

Khalilpour, R., Abbas, A., 2014b. Physico-Chemical Property Models of MEA-based Postcombustion Carbon Capture Process, in: Sharma, U.C., Kumar, S., Prasad, R. (Eds.), Energy Science and Technology: Opportunities and Challenges. Studium Press LLC, USA.

Lawal, A., Wang, M. H., Stephenson, P., Obi, O., 2012. Demonstrating full-scale post-combustion $\mathrm{CO}_{2}$ capture for coal-fired power plants through dynamic modelling and simulation. Fuel 101, 115-128.

Luo, X., Knudsen, J.N., de Montigny, D., Sanpasertparnich, T., Idem, R., Gelowitz, D., Notz, R., Hoch, S., Hasse, H., Lemaire, E., Alix, P., Tobiesen, F.A., Juliussen, O., Kopckeh, M., Svendsen, H.F., 2009. Comparison and validation of simulation codes against sixteen sets of data from four different pilot plants. Enrgy Proced 1, 1249-1256.

Mac Dowell, N., Shah, N., 2015. The multi-period optimisation of an amine-based CO2 capture process integrated with a super-critical coal-fired power station for flexible operation. Computers \& Chemical Engineering 74, 169-183.

Metz, B., Davidson, O., Coninck, H.d., Loos, M., Meyer, L., 2005. IPCC special report on carbon dioxide capture and storage. Cambridge University Press, for the Intergovernmental Panel on Climate Change, Cambridge.

Mores, P., Scenna, N., Mussati, S., 2011. Post-combustion $\mathrm{CO}_{2}$ capture process: Equilibrium stage mathematical model of the chemical absorption of $\mathrm{CO}_{2}$ into monoethanolamine (MEA) aqueous solution. Chem Eng Res Des 89, 1587-1599.

Pandya, J.D., 1983. Adiabatic Gas-Absorption and Stripping with Chemical-Reaction in Packed Towers. Chem Eng Commun 19, 343-361.

Peters, M.S., Timmerhaus, K.D., West, R.E., 2003. Plant Design and Economics for Chemical Engineers. McGraw-Hill.

Rubin, E.S., Chen, C., \& Rao, A. B., 2007. Cost and performance of fossil fuel power plants with $\mathrm{CO}_{2}$ capture and storage. Energy policy 35, 4444-4454.

Rubin, E.S., Short, C., Booras, G., Davison, J., Ekstrom, C., Matuszewski, M., \& McCoy, S. , 2013. A proposed methodology for $\mathrm{CO}_{2}$ capture and storage cost estimates. International Journal of Greenhouse Gas Control 17, 488-503.

Sanyal, D., Vasishtha, N., Saraf, D.N., 1988. Modeling of Carbon-Dioxide Absorber Using Hot Carbonate Process. Ind Eng Chem Res 27, 2149-2156.

Turton, R., Bailie, R.C., Whiting, W.B., 2009. Analysis, synthesis, and design of chemical processes. Prentice Hall.

Turton, R., Bailie, R.C., Whiting, W.B., Shaeiwitz, J.A., 2008. Analysis, Synthesis and Design of Chemical Processes. Pearson Education.

van der Spek, M., Ramirez, Andrea., Faaij, André., 2017a. Challenges and uncertainties of ex ante techno-economic analysis of low TRL $\mathrm{CO}_{2}$ capture technology: Lessons from a case study of an NGCC with exhaust gas recycle and electric swing adsorption. Applied Energy.

van der Spek, M., Sanchez Fernandez, Eva., Eldrup, Nils Henrik., Skagestad, Ragnhild., Ramirez, Andrea., Faaij, André., , 2017b. Unravelling uncertainty and variability in early stage technoeconomic assessments of carbon capture technologies. International Journal of Greenhouse Gas Control 56, 221-236.

Wang, Y., Zhao, Li., Otto, Alexander., Robinius, Martin., Stolten, Detlef., 2017. A Review of Post-combustion $\mathrm{CO}_{2}$ Capture Technologies from Coal-fired Power Plants. Energy Procedia 114, $46 \quad 650-665$. 
